\title{
Intracranial Hemorrhage in Eclampsia: An Unusual Case Report
}

\author{
Sangeeta Pahwa ${ }^{1}$, Tavleen Kaur ${ }^{2}$, Arshdeep Kaur ${ }^{3}$
}

\begin{abstract}
Though cerebrovascular accident in hypertensive disorders of pregnancy is a rare entity, it causes high morbidity and mortality because of unpredictable onset and late diagnosis. Incidence of intracranial hemorrhage (ICH) accompanying nonfatal eclampsia is unknown, but the lesion is found in $10-60 \%$ of all mortalities that occur due to eclampsia.

We report an unusual case of a 25 -year-old primigravida who developed sudden eclampsia and intracranial hemorrhage leading to a mass effect on the right ventricle and a midline shift. She was managed by a multidisciplinary approach involving an emergency lower section cesarean section by an obstetrician, a craniotomy by a neurosurgeon, and intensive care by an anesthesiologist.

Keywords: Craniotomy, Eclampsia, Glascow coma scale, Intracranial hemorrhage.

AMEl's Current Trends in Diagnosis \& Treatment (2020): 10.5005/jp-journals-10055-0097
\end{abstract}

\section{INTRODUCTION}

Gestational hypertension is defined as a blood pressure of $140 / 90 \mathrm{~mm} \mathrm{Hg}$ or more for the first time in pregnancy after 20 weeks of gestation with incidence of 3-10\% of all pregnancies but in association with severe features of HELLP syndrome (hemolysis, elevated liver enzymes, and low platelets) seen in 9.5/1000 deliveries. ${ }^{1}$

Preeclampsia is the most common risk factor of $\mathrm{ICH}$ in pregnancy. ICH is a rare, yet potentially devastating and lifethreatening complication of pregnancy, associated with significant maternal morbidity and mortality. Though preeclampsia affects all the organs of the body but ICH is the end-stage manifestation of preeclampsia.

\section{Case Report}

We report the case of a 25 -year-old primigravida $35+3$ weeks by gestation who was brought to emergency in an unconscious state. As per history given by attendants, she had a severe headache with fits at home and was brought to obstetrics and gynecology emergency. There was no history of fits or trauma in the past and no significant medical history. On examination, her vitals were as follows: pulse rate (PR): $88 / \mathrm{min}$, (blood pressure) BP: $150 / 100 \mathrm{~mm} \mathrm{Hg}$, respiratory rate (RR): $20 / \mathrm{min}$, and oxygen saturation $\left(\mathrm{SpO}_{2}\right)$ : $98 \%$. Obstetrical examination revealed uterine size (36 weeks) corresponding to the period of amenorrhea, fetal heart sounds present, regular @148bpm. Fundus examination was normal and all her relevant investigations like platelet count, liver and renal function test, uric acid, lactate dehydrogenase (LDH) levels, and electrocardiogram (ECG) were done.

The patient was given intravenous (i.v.) labetolol for hypertension and Pritchard regimen of magnesium sulphate for convulsions. As the cervical score was unfavorable, she was taken up for an emergency (lower segment cesarean section) LSCS after stabilizing the patient. A healthy female baby of $2.5 \mathrm{~kg}$ was delivered. Postoperatively, the patient was shifted to ICU due to a persistently low Glasgow coma score (GCS) (4/15), an urgent neurosurgery and neurology consultation was undertaken, a CT angiography was advised (Fig. 1) which showed a large area of hemorrhage involving the right capsule-ganglionic and right
${ }^{1-3}$ Department of Obstetrics and Gynaecology, Sri Guru Ram Das Institute of Medical Sciences and Research, Amritsar, Punjab, India

Corresponding Author: Sangeeta Pahwa, Department of Obstetrics and Gynaecology, Sri Guru Ram Das Institute of Medical Sciences and Research, Amritsar, Punjab, India, Phone: +91 9855080215, e-mail: sangeetadr30@gmail.com

How to cite this article: Pahwa S, Kaur T, Kaur A. Intracranial Hemorrhage in Eclampsia: An Unusual Case Report. AMEl's Curr Trends Diagn Treat 2020;4(2):105-106.

Source of support: Nil

Conflict of interest: None

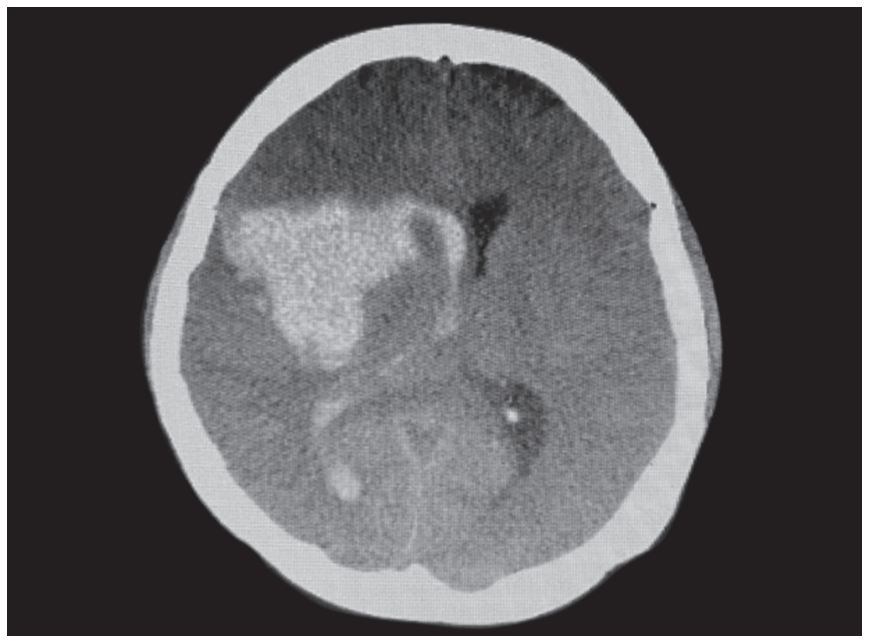

Fig. 1: Right parenchymal and intraventricular hemorrhage

thalamic area with surrounding edema causing a mass effect on the right lateral ventricle and a midline shift of $8 \mathrm{~mm}$. the patient was shifted for an urgent craniotomy where a decompressive surgery was done.

Post craniotomy, the patient was put on injection labetolol i.v., with ventilatory support as per the neurosurgery department. 
Patient started improving and was discharged on day 22 in a neurologically stable condition without any motor or sensory deficits.

\section{Discussion}

Intracranial hemorrhage $(\mathrm{ICH})$ is a devastating condition regardless of pregnancy status and can lead to long-term disabilities or death. Subarachnoid hemorrhage $(\mathrm{SAH})$ and intraparenchymal hemorrhage $(\mathrm{IPH})$ represent _ $<50 \%$ of hemorrhagic strokes encountered in pregnant women. The most common causes of $\mathrm{ICH}$ in pregnant women are from vascular malformations, such as AVMs, aneurysms or Moyamoya disease. The estimated pregnancyassociated $\mathrm{ICH}$ rate ranges from 3.8 to 18.1 per $1,00,000^{2}$ deliveries. Mortality rate resulting from pregnancy-associated $\mathrm{ICH}$ ranges from 9 to $38 \%$ and permanent neurologic deficits occur in $40 \%$ patients. Preeclampsia plays a pivotal role in the development of pregnancy-associated ICH. The possible contributions include endothelial dysfunction, microangiopathy and vasospasm of the brain vessels, increased cerebral perfusion pressure, brain capillary permeability, disturbances of cerebral blood flow, autoregulation and subsequent cerebral hyperperfusion leading to vasodilation and brain edema, thrombocytopenia or coagulation factors. ${ }^{3}$ The incidence of pregnancy-associated ICH is highest during the postpartum period.

The most important risk factor for $\mathrm{ICH}$ is hypertension. Additionally, age _> 30 years is an independent risk factor for $\mathrm{ICH}$ in pregnancy-induced hypertension $(\mathrm{PIH})$ patients but our patient was young. Our patient was primigravida which is a high risk factor for $\mathrm{PIH}$ and its complications. Infrequent antenatal care (ANC) visits are also a risk factor for complications leading to $\mathrm{ICH}$. As the patient had no regular ANC visits, no blood pressure recordings were available and at what BP ICH occurred cannot be made out.
Regular antenatal visits are mandatory if we want to decrease the risk of $\mathrm{ICH}$ in any patient with gestational hypertension. To conclude, eclampsia itself is a deadly complication of pregnancyinduced hypertension. ${ }^{4}$ Nowadays, eclampsia is less frequently seen because of cost-effective, easily available, and efficient ANC visits; it is now only seen in patients who neglect their ANC and do not come timely whenever a complication arises. Our goal is to keep the diastolic BP between $90 \mathrm{~mm} \mathrm{Hg}$ and $100 \mathrm{~mm} \mathrm{Hg}$ for the prevention of cerebral hemorrhage. Cerebral complications can be avoided if the eclampsia is managed early by instituting timely treatment.

\section{Conclusion}

As in this case, the patient was managed in a tertiary healthcare center, where a multidisciplinary approach was undertaken and highly equipped ICU facilities were available, we were able to save the patient. Every patient with high risk factors (primigravida with $\mathrm{PIH}$ ) should undergo institutional delivery where advanced anesthetic team, obstetric team, neonatologist, neurosurgery, and neurologist are available.

\section{References}

1. Miniño AM, Heron MP, Murphy SL, et al. Deaths: final data for 2004 Nat Vital Stat Rep 2007;55(19):1-119. Available at: http://www.cdc. gov/nchs/data/nvsr/nvsr55/nvsr55_19.pdf [accessed on Nov 4, 2007].

2. Sibai BM, Caritis S, Hauth J. What we have learned about preeclampsia. Semin Perinatol 2003;27(3):239-246. DOI: 10.1016/ s0146-0005(03)00022-3.

3. ACOG Committee on Practice Bulletins-Obstetrics. ACOG practice bulletin. Diagnosis and management of preeclampsia and eclampsia. Number 33, January 2002. Obstet Gynecol 2002;99(1):159-167. DOI: 10.1016/s0029-7844(01)01747-1.

4. Lindheimer MD, Taler SJ, Cunningham FG. Hypertension in pregnancy. J Am Soc Hypertens 2008;2(6):484-494. DOI: 10.1016/j. jash.2008.10.001. 